\title{
Muscle strength and hop performance criteria prior to return to sports after ACL reconstruction
}

Roland Thomee, Yonatan Kaplan, Joanna Kvist, Grethe Myklebust, May Arna Risberg, Daniel Theisen, Elias Tsepis, Suzanne Werner, Barbara Wondrasch and Erik Witvrouw

\section{Linköping University Post Print}

N.B.: When citing this work, cite the original article.

The original publication is available at www.springerlink.com:

Roland Thomee, Yonatan Kaplan, Joanna Kvist, Grethe Myklebust, May Arna Risberg, Daniel Theisen, Elias Tsepis, Suzanne Werner, Barbara Wondrasch and Erik Witvrouw, Muscle strength and hop performance criteria prior to return to sports after ACL reconstruction, 2011, Knee Surgery, Sports Traumatology, Arthroscopy, (19), 11, 1798-1805. http://dx.doi.org/10.1007/s00167-011-1669-8

Copyright: Springer Verlag (Germany) http://www.springerlink.com/

Postprint available at: Linköping University Electronic Press http://urn.kb.se/resolve?urn=urn:nbn:se:liu:diva-73103 


\section{Muscle strength and hop performance criteria prior to return to sports after ACL reconstruction}

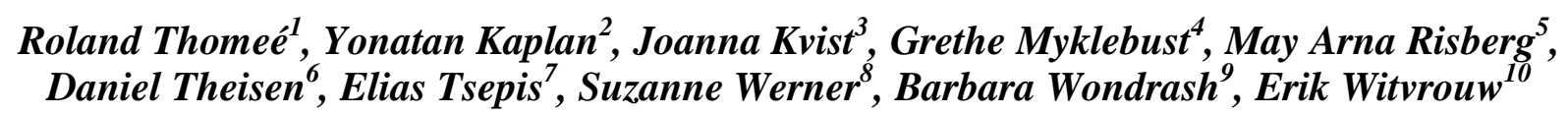

European Board of Sports Rehabilitation (EBSR)

1 Department of Orthopaedics, Sahlgrenska University Hospital, Göteborg University, Göteborg, Sweden

2 Physical Therapy and Sports Medicine Institute Lerner Sports Center, Hebrew University of Jerusalem, Israel

3 Division of Physiotherapy, Department of Health and Society, Faculty of Health Sciences, Linköping University, Linköping, Sweden

4 Oslo Sport Trauma Research Center, Norwegian School of Sports Sciences, Oslo, Norway

5 Norwegian School of Sport Sciences, Hjelp24NIMI and Orthopaedic Department, Oslo University Hospital, Oslo, Norway

6 Sports Medicine Research Laboratory, Luxembourg

7 Department of Orthopaedic Surgery, Orthopaedic Sports Medicine Center of Ioannina, University of Ioannina, Ioannina, Greece.

8 Stockholm Sports Trauma Research Center, Department of Molecular Medicine and Surgery, Karolinska institute, Stockholm, Sweden

9 Vienna Sports Medicine Center, Wien, Austria

10 Department of Rehabilitation Sciences and Physical Therapy, Ghent University, Ghent, Belgium

Corresponding author:

Roland Thomeé, RPT, Associate Professor

Lundberg Laboratory for Orthopaedic Research

Department of Orthopaedics

Sahlgrenska University Hospital

SE-413 45 Göteborg, Sweden

Fax: +46 31151538

Phone: +46 705987023

E-mail: roland.thomee@ orthop.gu.se 


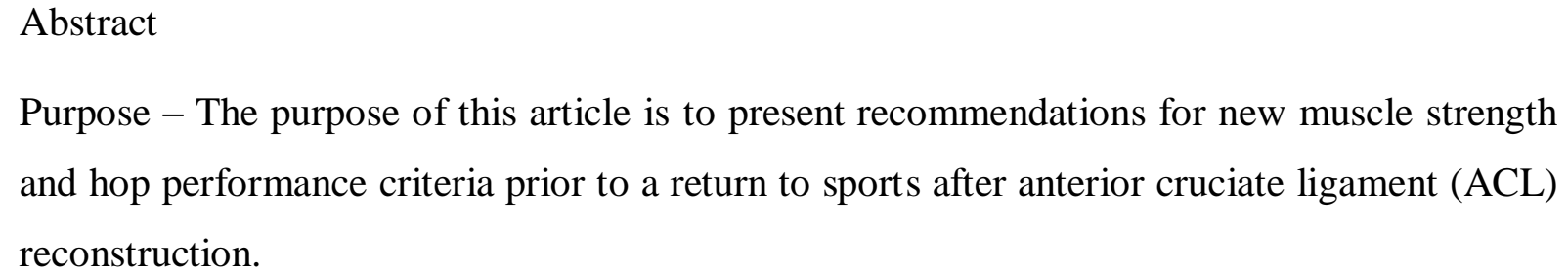

Purpose - The purpose of this article is to present recommendations for new muscle strength and hop performance criteria prior to a return to sports after anterior cruciate ligament (ACL) reconstruction.

Methods - A search was made of relevant literature relating to muscle function, self-reported questionnaires on symptoms, function and knee-related quality of life, as well as the rate of re-injury, the rate of return to sports and the development of osteoarthritis (OA) after ACL reconstruction. The literature was reviewed and discussed by the European Board of Sports Rehabilitation (EBSR) in order to reach consensus on criteria for muscle strength and hop performance prior to a return to sports.

Results - The majority of athletes that sustain an (ACL) injury do not successfully return to their pre-injury sport, even though most athletes achieve what is considered to be acceptable muscle function. On self-reported questionnaires, the athletes report high ratings for fear of re-injury, low ratings for their knee function during sports and low ratings for their kneerelated quality of life.

Conclusion - The conclusion is that the muscle function tests that are commonly used are not demanding enough or not sensitive enough to identify differences between injured and noninjured sides. Recommendations for new criteria are given for the sports medicine community to consider, before allowing an athlete to return to sports after an ACL reconstruction.

\section{Level of evidence: Level IV}

Key words: return to sport, strength, hop performance, patient's opinion, knee function 


\section{Introduction}

The majority of athletes that sustain an anterior cruciate ligament (ACL) injury do not successfully return to their pre-injury sport [8,9]. One major reason for this could be that the athletes do not regain their pre-injury muscle function. A recent review concluded that, even though the vast majority (85-90\%) obtained what were regarded as normal or near normal strength values, the return to sport rate was low [9]. Fear of re-injury was the most common reason for giving up sports participation or for returning to a lower level of sports [9]. Furthermore, recent studies report that patients that had undergone ACL reconstruction had $\geq 90 \%$ muscle function capacity in their injured leg compared with their non-injured leg and, at the same time, reported poor results when it came to rating their knee function during sports as well as their knee-related quality of life [2,91,61,67,66]. The results in muscle function tests do not harmonise well with the patients' own experiences and their scores for self-reported outcome measures. The interpretation of this discrepancy could be that the muscle function tests that are commonly used are not demanding enough or not sensitive enough to identify differences between injured and non-injured sides. Additionally, when tested during fatigued conditions one year after ACL reconstruction, only two thirds of the athletes performed satisfactorily, despite the fact that they had $\geq 90 \%$ hop capacity when not fatigued [11]. Again, this indicates that the muscle function criteria that are commonly used are not sufficient.

The members of the European Board of Sports Rehabilitation (EBSR) searched, reviewed and discussed relevant literature in order to reach consensus on criteria for muscle strength and hop performance prior to a return to sports after an ACL reconstruction. 


\section{A successful return to sports}

There are many factors to consider when making the decision about when to allow a patient to return to sport. Creighton and co-workers [21] have outlined a decision-based return to play model comprising three steps. Step 1 involves medical factors for evaluating the patient's health status, such as demographics, medical history, symptoms and signs. Step 2 involves sport risk modifiers, such as the type and level of sport, for evaluating risks if the patient returns to sport, while Step 3 involves decision modifiers, such as season, internal and external pressure and conflict of interest. The present article focuses on criteria for muscle function in Step 1, which is important for the risk evaluation process.

The definition of a successful return to sport is unclear in the literature. It needs to be clarified whether the return is to a pivoting or non-pivoting sport, contact or non-contact sport, the same pre-injury sport and same competitive level, the same sport but on a lower level, a different sport, or that the athlete merely perceives that the return to sport is successful $[8,47,55,76]$. Furthermore, it is unclear how long the athlete needs to maintain that specific level of sporting ability, before it can be claimed that the return was successful. Can it be accepted as a successful return to sports if, after one, three or 12 months, the athlete sustains a re-injury, contralateral injury or a subsequent injury to another structure? For this reason, the use of the term return to sport must be accompanied by a detailed description of the type and level of activity, as well as the time of return and duration of participation.

A successful return to sport in the short term means a low risk of re-injury $[56,83,5,89,68]$. ACL re-injury occurs in $6 \%$ to $13 \%$ of ACL reconstructed knees $[57,83,95]$ and $2-6 \%$ sustain a contralateral ACL injury $[89,83,102]$. It has been reported that, in elite Alpine skiing, as many as $30 \%$ of the ACL-injured skiers sustain an ACL injury in the contralateral knee [77].

In the long term, a successful return to sport means that there is a low risk of developing knee osteoarthrosis (OA) [50,101,60,5,64-66]. Several risk factors for the development of knee OA after ACL injury are reported in the literature [75,41,84,85,24]. A systematic review discussed whether the risk of developing knee OA might be somewhat exaggerated in the literature [64]. It has been stated that $50 \%$ of patients with an ACL injury [49] and 70\% of the patients that also have a meniscal injury will develop knee OA [27]. The systematic review concluded that there was a knee OA prevalence of 0-13\% 10-15 years after an isolated ACL injury and that patients with combined ACL and meniscal injuries had a prevalence of $21 \%$ $48 \%$ [64]. Strong evidence identifying meniscal injury and meniscectomy as risk factors for 
the development of knee OA after ACL injury was found [64]. However, the results in a development of knee OA [75] and muscle weakness is commonly suggested to be a risk factor [24]. It has further been suggested that neuromuscular function may be of importance in preventing knee OA $[81,100,71,40]$ and that poor muscle function might be a predictor of OA development $[92,93,75]$. It is possible that early neuromuscular rehabilitation resulting in good knee function and a modification of physical activity could reduce the risk of developing knee $\mathrm{OA}$ in the long run after ACL injury [42].

It seems clear that, within the first year after surgery, far from all athletes with an ACL injury return to their pre-injury level of sport. Ardern and co-workers [8] found that as many as two thirds of the athletes that had undergone ACL reconstruction had not returned to the same competitive level of sport 12 months after surgery. Their analysis of return to sport outcomes in six other studies $[20,32,45,87,96,58]$ showed that $75 \%$ of the athletes returned to some form of sports activity. Sixty-four per cent returned to competitive sports, but not necessarily at the same level as pre-injury. It also seems clear that females (26\%) have a much lower rate of successful return to the same pre-injury level of sport compared with males (37\%), even though females and males appear to have the same intentions to return to sport [8].

Despite the seemingly low rate of athletes that actually do return to the same pre-injury level of sport within the first year after surgery, the recommendations that are given to the ACL-injured athlete on when to return to sport usually range between 3 and 9 months $[43,8,86]$.

\section{Factors affecting the ability to return to sports}

Many factors that affect an injured athlete's ability to return successfully to sports after an ACL injury have been suggested. The most common factors discussed in the literature are the pre-injury status of the athlete, associated knee injuries, time to treatment, time to surgery, surgical technique, knee kinematics after injury/surgery, rehabilitation protocol, compliance, functional knee stability, knee symptomatology and the level/intensity of the sport $[9,3,8,15,16,19,21-23,29,88,14,13]$. The achieved level of muscle function $[2,12,23,34,46,53,59,72,79,97]$, psychological factors, such as fear of re-injury and low selfefficacy beliefs, the patients' "desired" physical activity level and social factors, such as 
family or work career, are also frequently discussed $[44,29,28,37,38,45,54,90,94,63,64,18,8,47]$.

Furthermore, it has been noted that patients' compliance decreases over time during the rehabilitation process [13]. ACL-reconstructed athletes express frustration that the progress during rehabilitation is much slower than they had expected. As a result, the compliance of some patients decreases, some will even give up, while others increase their efforts and continue with their rehabilitation [32].

\section{Muscle function}

Restored lower extremity muscle function, such as knee extensor and flexor muscle strength and one-legged jumping ability, is considered to be important after an ACL reconstruction in order successfully to return to sports or physical activity $[35,57,10,48,47,49,75,2,23]$. It remains unclear whether patients with an ACL reconstruction sufficiently restore their muscle function, since most studies only report results at group level, which are between $70-90 \%$ of the non-injured leg $[7,52,73,70,17,74,80,99,104,39,4,6,36,51,82,58]$. It is furthermore unclear whether the graft choice influences the recovery of muscle function. A recent meta-analysis indicated that patients with bone-patellar tendon-bone autograft have greater deficits in extensor muscle strength and a lower deficit in flexor muscle strength compared with hamstring autograft [103]. In a 2- to 5-year follow-up, Ageberg and co-workers [2] did not find any differences between patients who, in a randomised clinical trial (RCT) [25], had undergone surgical reconstruction and rehabilitation and those patients who had been treated solely with rehabilitation. This indicates that reconstructive surgery may not be a prerequisite for restoring muscle function.

The limb symmetry index (LSI) has been the most frequently reported criterion for assessing whether muscle strength and hop performance are normal or abnormal, i.e. that the capacity of the injured leg is, or is not, as good as that of the non-injured leg. The rationale is to ensure that the injured leg reaches an acceptable LSI level in order to minimise overuse and/or acute injury when returning to sport or strenuous work [10]. An LSI of $<90 \%$, i.e. more than $10 \%$ difference between limbs following ACL injury and reconstruction, has been regarded as unsatisfactory for both strength and hop performance. One major problem with the LSI in research is that it conceals individual results, which can be revealed if, for example, the results are presented as success rates, i.e. the proportion of patients that reach an 
acceptable LSI. Long-term follow-ups of patients with an ACL injury indicate that muscle

\section{Battery of muscle function tests}

When it comes to the assessment of strength and functional performance after ACL reconstruction, the concept of a "battery of tests" has been suggested in order to measure strength and hop performance [19,21,22,59,30]. A battery of tests, including three different tests for lower extremity muscle strength (leg extension, leg flexion and leg press) and three different hop tests (vertical jump, hop for distance and side hop), has been shown to be reliable and to have a greater ability, compared with any single test, when it comes to discriminating between the injured and non-injured sides in patients after an ACL injury and those who have undergone ACL reconstruction [59,30]. When evaluating each test in the battery of tests separately, the patients had, at group level, reached $\geq 90 \%$ of the capacity in their injured leg at both the 1- and 2-year follow-up [91]. When using the more demanding criteria for a successful outcome in terms of muscle function, i.e. that the patients should reach $\geq 90 \%$ on all the tests in the battery, the results were considered poor. Fewer than $50 \%$ of the patients were successful when using the more demanding criteria of $\geq 90 \%$ in all three tests in the strength test battery or $\geq 90 \%$ in all three tests in the hop test battery. Similarly, by increasing the acceptable LSI level from $\geq 90 \%$ to $\geq 95 \%$ or $\geq 100 \%$, the results were naturally poorer for each of the individual tests in the battery of tests. Finally, when using the criteria of reaching an LSI of $\geq 100 \%$ in all three strength tests, as well as in all three hop tests, none of the patients had normal muscle function [91].

As previously stated, there appears to be a discrepancy between the patients' self-reported results for knee symptoms/function and the results of muscle function tests [8]. At a mean follow-up time of more than three years after ACL reconstruction, a recent review and metaanalysis by Ardern and co-workers [9] of 48 studies, evaluating 5,770 athletes with an ACL reconstruction, showed that $82 \%$ of the athletes had returned to some kind of sport, $63 \%$ to their pre-injury level and $44 \%$ to their pre-injury level of competitive sport. Patients with good hop performance were more likely to return to sport than patients with poor hop 
performance. Fear of re-injury was the most common reason for giving up sports participation satisfied with their knee function and that the criteria for muscle strength and hop performance are insufficient.

Furthermore, three recent studies report high LSI values for single muscle function tests two years after surgery, with scores of between 70 and 90 on the KOOS ${ }_{\text {Sports\&Recreation and }}$ between 65 and 75 on the $\operatorname{KOOS}_{\text {Quality-of-life }}[2,91,61]$. The same pattern has recently been reported at two years and 10-15 years after ACL surgery $[67,66]$. This could mean that the muscle function tests that are commonly used are not demanding enough or not sensitive enough to identify differences between the injured and non-injured sides and muscle function results do not correlate with patients' experience and reported outcome measures.

Athletes that had returned to sports were classified as having unsatisfactory hop capacity when they were tested during fatigued conditions one year after ACL surgery [11]. All the subjects had $\geq 90 \%$ hop capacity in their ACL-reconstructed leg compared with the noninjured leg during non-fatigued conditions. However, when the quadriceps muscle was fatigued, the ACL-reconstructed leg was unable to perform satisfactorily in two thirds of the subjects. Again, it is likely that the muscle function tests that are commonly used are not sensitive enough to identify differences between injured and non-injured sides.

Muscle function deficits following ACL reconstruction can be due to insufficient rehabilitation protocols [74]. It is possible to speculate that ACL rehabilitation protocols focus too heavily on functional low-loading and sport-specific exercises. As a result, weight training intensity might be too low to increase muscle strength and muscle volume to satisfactory levels. A 12-week eccentric resistance training programme, implemented as early as three weeks after ACL reconstruction, resulted in greater increases in muscle volume and muscle function of the quadriceps and gluteus maximus muscles compared with a standard rehabilitation protocol [26]. As increases in muscle strength and volume take a considerable length of time [98], it may be possible that the time that the patients spend on weight training during rehabilitation is in fact, in most cases, insufficient.

In order to obtain good muscle function after ACL reconstruction, three factors have been found to be predictors of outcome; good pre-operative quadriceps strength [23], little or no pre-operative anterior knee pain [31] and high self-efficacy of knee function [90]. 
In order to match the patients' low rate of return to sports and their low scores for sports ability and knee-related quality of life, as well as to minimise the negative short- and longterm consequences for those that do return to sports, the criteria that are commonly used for muscle function should be revised. This means that more precise, demanding criteria for muscle function are needed. Rehabilitation protocols should therefore be further developed to be more effective and/or more time needs to be spent on muscle function rehabilitation.

The recommendations of the EBSR relating to muscle function in individuals that have undergone ACL reconstruction are based on what is published in the scientific literature, as well as clinical and research experience among the members of the EBSR.

Please observe that the recommendations (Table 1) are based on comparisons with the non-injured leg. No data are as yet available in the literature in terms of absolute muscle strength and hop value levels for different sports. Furthermore, we do not make any recommendations for eccentric strength criteria, as not enough data are available in the literature. Muscle function is naturally far more complex than knee extensor strength, knee flexor strength and one-legged hop capacity. Aspects of muscle function, such as lower extremity strength performance in other situations or the importance of motor control, have not been considered in the present article. 


\section{EBSR recommendations}

1. Reports on a return to sport must be accompanied by a detailed description of the type and level of sport, as well as the time of return and duration of participation.

2. Muscle strength and hop performance must be presented as both absolute values and the LSI.

3. LSI values must be presented at group level, together with success rates, i.e. the proportion of patients that achieve an acceptable LSI.

Table 1 - Recommended criteria for strength and hop performance prior to a return to sport after ACL reconstruction.

\begin{tabular}{|c|c|c|}
\hline Type of sport & $\begin{array}{c}\text { LSI } \\
\text { strength }\end{array}$ & $\begin{array}{c}\text { LSI } \\
\text { hop performance }\end{array}$ \\
\hline $\begin{array}{c}\text { Pivoting } \\
\text { Contact } \\
\text { Competitive }\end{array}$ & $\begin{array}{c}\mathbf{1 0 0 \%} \text { on } \\
\text { knee-extensor } \text { as well as } \\
\text { knee-flexor strength }\end{array}$ & $\begin{array}{c}\mathbf{9 0 \%} \text { on } \\
\text { two maximum }{ }^{\#} \text { as well as } \\
\text { one endurable }\end{array}$ \\
\hline $\begin{array}{c}\text { Non-pivoting } \\
\text { Non-contact } \\
\text { Recreational }\end{array}$ & $\begin{array}{c}\mathbf{9 0 \%} \text { on } \\
\text { knee-extensor } \text { as well as } \\
\text { knee-flexor strength }\end{array}$ & $\begin{array}{c}\mathbf{9 0 \%} \text { on } \\
\text { one maximum } \\
\text { one endurable }\end{array}$ \\
\hline
\end{tabular}

\# For example, a vertical jump and a hop for distance [62,69,30,78]

For example, the triple jump [78], stair hop [78] or side hop test [30] 


\section{References}

1. Ageberg E, Pettersson A, Friden T (2007) 15-year follow-up of neuromuscular function in patients with unilateral nonreconstructed anterior cruciate ligament injury initially treated with rehabilitation and activity modification: a longitudinal prospective study. Am J Sports Med 35 (12):2109-2117.

2. Ageberg E, Thomee R, Neeter C, Silbernagel KG, Roos EM (2008) Muscle strength and functional performance in patients with anterior cruciate ligament injury treated with training and surgical reconstruction or training only: a two to five-year followup. Arthritis Rheum 59 (12):1773-1779.

3. Alentorn-Geli E, Myer GD, Silvers HJ, Samitier G, Romero D, Lazaro-Haro C, Cugat R (2009) Prevention of non-contact anterior cruciate ligament injuries in soccer players. Part 2: a review of prevention programs aimed to modify risk factors and to reduce injury rates. Knee Surg Sports Traumatol Arthrosc 17 (8):859-879.

4. Anderson JL, Lamb SE, Barker KL, Davies S, Dodd CA, Beard DJ (2002) Changes in muscle torque following anterior cruciate ligament reconstruction: a comparison between hamstrings and patella tendon graft procedures on 45 patients. Acta Orthop Scand 73 (5):546-552.

5. Andersson D, Samuelsson K, Karlsson J (2009) Treatment of anterior cruciate ligament injuries with special reference to surgical technique and rehabilitation: an assessment of randomized controlled trials. Arthroscopy 25 (6):653-685.

6. Andrade MS, Cohen M, Picarro IC, Silva AC (2002) Knee performance after anterior cruciate ligament reconstruction. Isokinetics Exerc Sci 10:81-86.

7. Arangio GA, Chen C, Kalady M, Reed JF, 3rd (1997) Thigh muscle size and strength after anterior cruciate ligament reconstruction and rehabilitation. J Orthop Sports Phys Ther 26 (5):238-243.

8. Ardern CL, Webster KE, Taylor NF, Feller JA (2010) Return to the Preinjury Level of Competitive Sport After Anterior Cruciate Ligament Reconstruction Surgery: Twothirds of Patients Have Not Returned by 12 Months After Surgery. Am J Sports Med. 0363546510384798 [pii] 10.1177/0363546510384798

9. Ardern CL, Webster KE, Taylor NF, Feller JA (2011) Return to sport following anterior cruciate ligament reconstruction surgery: a systematic review and meta-analysis of the state of play. Br J Sports Med. bjsm.2010.076364 [pii]10.1136/bjsm.2010.076364

10. Augustsson J, Thomee R, Karlsson J (2004) Ability of a new hop test to determine functional deficits after anterior cruciate ligament reconstruction. Knee Surg Sports Traumatol Arthrose 12 (5):350-356.

11. Augustsson J, Thomee R, Linden C, Folkesson M, Tranberg R, Karlsson J (2006) Singleleg hop testing following fatiguing exercise: reliability and biomechanical analysis. Scand J Med Sci Sports 16 (2):111-120.

12. Beutler A, de la Motte S, Marshall S, Padua D, Boden B (2009) Muscle Strength and Qualitative Jump-Landing Differences in Male and Female Military Cadets: The Jump-Acl Study. J Sports Sci Med 8:663-671.

13. Beynnon BD, Johnson RJ, Fleming BC (2002) The science of anterior cruciate ligament rehabilitation. Clin Orthop Relat Res (402):9-20.

14. Beynnon BD, Uh BS, Johnson RJ, Abate JA, Nichols CE, Fleming BC, Poole AR, Roos H (2005) Rehabilitation after anterior cruciate ligament reconstruction: a prospective, randomized, double-blind comparison of programs administered over 2 different time intervals. Am J Sports Med 33 (3):347-359.

15. Boden BP, Sheehan FT, Torg JS, Hewett TE (2010) Noncontact anterior cruciate ligament injuries: mechanisms and risk factors. J Am Acad Orthop Surg 18 (9):520-527. 
16. Button K, van Deursen R, Price P (2006) Classification of functional recovery of anterior cruciate ligament copers, non-copers, and adapters. Br J Sports Med 40 (10):853-859; discussion 859.

17. Carter TR, Edinger S (1999) Isokinetic evaluation of anterior cruciate ligament reconstruction: hamstring versus patellar tendon. Arthroscopy 15 (2):169-172.

18. Cheatham SA, Johnson DL (2010) Current concepts in ACL Injuries. Phys Sportsmed 38 (3):61-68.

19. Clover J, Wall J (2010) Return-to-play criteria following sports injury. Clin Sports Med 29 (1):169-175, table of contents.

20. Colombet P, Allard M, Bousquet V, de Lavigne C, Flurin PH, Lachaud C (2002) Anterior cruciate ligament reconstruction using four-strand semitendinosus and gracilis tendon grafts and metal interference screw fixation. Arthroscopy 18 (3):232-237.

21. Creighton DW, Shrier I, Shultz R, Meeuwisse WH, Matheson GO (2010) Return-to-play in sport: a decision-based model. Clin J Sport Med 20 (5):379-385.

22. Dauty M, Le Brun J, Huguet D, Paumier S, Dubois C, Letenneur J (2008) [Return to pivot-contact sports after anterior cruciate ligament reconstruction: patellar tendon or hamstring autografts]. Rev Chir Orthop Reparatrice Appar Mot 94 (6):552-560.

23. Eitzen I, Holm I, Risberg MA (2009) Preoperative quadriceps strength is a significant predictor of knee function two years after anterior cruciate ligament reconstruction. $\mathrm{Br}$ J Sports Med 43 (5):371-376.

24. Felson DT, Lawrence RC, Dieppe PA, Hirsch R, Helmick CG, Jordan JM, Kington RS, Lane NE, Nevitt MC, Zhang Y, Sowers M, McAlindon T, Spector TD, Poole AR, Yanovski SZ, Ateshian G, Sharma L, Buckwalter JA, Brandt KD, Fries JF (2000) Osteoarthritis: new insights. Part 1: the disease and its risk factors. Ann Intern Med 133 (8):635-646.

25. Frobell RB, Roos EM, Roos HP, Ranstam J, Lohmander LS (2010) A randomized trial of treatment for acute anterior cruciate ligament tears. N Engl J Med 363 (4):331-342.

26. Gerber JP, Marcus RL, Dibble LE, Greis PE, Burks RT, LaStayo PC (2009) Effects of early progressive eccentric exercise on muscle size and function after anterior cruciate ligament reconstruction: a 1-year follow-up study of a randomized clinical trial. Phys Ther 89 (1):51-59.

27. Gillquist J, Messner K (1999) Anterior cruciate ligament reconstruction and the long-term incidence of gonarthrosis. Sports Med 27 (3):143-156.

28. Glazer DD (2009) Development and preliminary validation of the Injury-Psychological Readiness to Return to Sport (I-PRRS) scale. J Athl Train 44 (2):185-189.

29. Gobbi A, Francisco R (2006) Factors affecting return to sports after anterior cruciate ligament reconstruction with patellar tendon and hamstring graft: a prospective clinical investigation. Knee Surg Sports Traumatol Arthrosc 14 (10):1021-1028.

30. Gustavsson A, Neeter C, Thomee P, Silbernagel KG, Augustsson J, Thomee R, Karlsson J (2006) A test battery for evaluating hop performance in patients with an ACL injury and patients who have undergone ACL reconstruction. Knee Surg Sports Traumatol Arthrosc 14 (8):778-788.

31. Heijne A, Ang BO, Werner S (2009) Predictive factors for 12-month outcome after anterior cruciate ligament reconstruction. Scand J Med Sci Sports 19 (6):842-849.

32. Heijne A, Axelsson K, Werner S, Biguet G (2008) Rehabilitation and recovery after anterior cruciate ligament reconstruction: patients' experiences. Scand J Med Sci Sports 18 (3):325-335.

33. Hiemstra LA, Webber S, MacDonald PB, Kriellaars DJ (2000) Knee strength deficits after hamstring tendon and patellar tendon anterior cruciate ligament reconstruction. Med Sci Sports Exerc 32 (8):1472-1479. 
34. Holm I, Fosdahl MA, Friis A, Risberg MA, Myklebust G, Steen H (2004) Effect of neuromuscular training on proprioception, balance, muscle strength, and lower limb function in female team handball players. Clin J Sport Med 14 (2):88-94.

35. Itoh H, Kurosaka M, Yoshiya S, Ichihashi N, Mizuno K (1998) Evaluation of functional deficits determined by four different hop tests in patients with anterior cruciate ligament deficiency. Knee Surg Sports Traumatol Arthrosc 6 (4):241-245.

36. Jarvela T, Kannus P, Latvala K, Jarvinen M (2002) Simple measurements in assessing muscle performance after an ACL reconstruction. Int J Sports Med 23 (3):196-201.

37. Johnson U (1997) Coping strategies among long-term injured competitive athletes. A study of 81 men and women in team and individual sports. Scand J Med Sci Sports 7 (6):367-372.

38. Junge A (2000) The influence of psychological factors on sports injuries. Review of the literature. Am J Sports Med 28 (5 Suppl):S10-15.

39. Keays SL, Bullock-Saxton J, Keays AC, Newcombe P (2001) Muscle strength and function before and after anterior cruciate ligament reconstruction using semitendonosus and gracilis. Knee 8 (3):229-234.

40. Keays SL, Newcombe PA, Bullock-Saxton JE, Bullock MI, Keays AC (2010) Factors involved in the development of osteoarthritis after anterior cruciate ligament surgery. Am J Sports Med 38 (3):455-463.

41. Kessler MA, Behrend H, Henz S, Stutz G, Rukavina A, Kuster MS (2008) Function, osteoarthritis and activity after ACL-rupture: 11 years follow-up results of conservative versus reconstructive treatment. Knee Surg Sports Traumatol Arthrosc 16 (5):442-448.

42. Kostogiannis I, Ageberg E, Neuman P, Dahlberg L, Friden T, Roos H (2007) Activity level and subjective knee function 15 years after anterior cruciate ligament injury: a prospective, longitudinal study of nonreconstructed patients. Am J Sports Med 35 (7):1135-1143.

43. Kvist J (2004) Rehabilitation following anterior cruciate ligament injury: current recommendations for sports participation. Sports Med 34 (4):269-280.

44. Kvist J, Ek A, Sporrstedt K, Good L (2005) Fear of re-injury: a hindrance for returning to sports after anterior cruciate ligament reconstruction. Knee Surg Sports Traumatol Arthrosc 13 (5):393-397.

45. Langford JL, Webster KE, Feller JA (2009) A prospective longitudinal study to assess psychological changes following anterior cruciate ligament reconstruction surgery. $\mathrm{Br}$ J Sports Med 43 (5):377-378.

46. Lautamies R, Harilainen A, Kettunen J, Sandelin J, Kujala UM (2008) Isokinetic quadriceps and hamstring muscle strength and knee function 5 years after anterior cruciate ligament reconstruction: comparison between bone-patellar tendon-bone and hamstring tendon autografts. Knee Surg Sports Traumatol Arthrosc 16 (11):10091016.

47. Lee DY, Karim SA, Chang HC (2008) Return to sports after anterior cruciate ligament reconstruction - a review of patients with minimum 5-year follow-up. Ann Acad Med Singapore 37 (4):273-278.

48. Lee S, Seong SC, Jo H, Park YK, Lee MC (2004) Outcome of anterior cruciate ligament reconstruction using quadriceps tendon autograft. Arthroscopy 20 (8):795-802.

49. Lohmander LS, Englund PM, Dahl LL, Roos EM (2007) The long-term consequence of anterior cruciate ligament and meniscus injuries: osteoarthritis. Am J Sports Med 35 (10):1756-1769. 
50. Lohmander LS, Ostenberg A, Englund M, Roos H (2004) High prevalence of knee osteoarthritis, pain, and functional limitations in female soccer players twelve years after anterior cruciate ligament injury. Arthritis Rheum 50 (10):3145-3152.

51. Mattacola CG, Perrin DH, Gansneder BM, Gieck JH, Saliba EN, McCue FC, 3rd (2002) Strength, Functional Outcome, and Postural Stability After Anterior Cruciate Ligament Reconstruction. J Athl Train 37 (3):262-268.

52. McHugh MP, Tyler TF, Gleim GW, Nicholas SJ (1998) Preoperative indicators of motion loss and weakness following anterior cruciate ligament reconstruction. J Orthop Sports Phys Ther 27 (6):407-411.

53. Mikkelsen C, Werner S, Eriksson E (2000) Closed kinetic chain alone compared to combined open and closed kinetic chain exercises for quadriceps strengthening after anterior cruciate ligament reconstruction with respect to return to sports: a prospective matched follow-up study. Knee Surg Sports Traumatol Arthrosc 8 (6):337-342.

54. Morrey MA, Stuart MJ, Smith AM, Wiese-Bjornstal DM (1999) A longitudinal examination of athletes' emotional and cognitive responses to anterior cruciate ligament injury. Clin J Sport Med 9 (2):63-69.

55. Myklebust G, Bahr R (2005) Return to play guidelines after anterior cruciate ligament surgery. Br J Sports Med 39 (3):127-131.

56. Myklebust G, Engebretsen L, Braekken IH, Skjolberg A, Olsen OE, Bahr R (2003) Prevention of anterior cruciate ligament injuries in female team handball players: a prospective intervention study over three seasons. Clin J Sport Med 13 (2):71-78.

57. Myklebust G, Holm I, Maehlum S, Engebretsen L, Bahr R (2003) Clinical, functional, and radiologic outcome in team handball players 6 to 11 years after anterior cruciate ligament injury: a follow-up study. Am J Sports Med 31 (6):981-989.

58. Nakayama Y, Shirai Y, Narita T, Mori A, Kobayashi K (2000) Knee functions and a return to sports activity in competitive athletes following anterior cruciate ligament reconstruction. J Nippon Med Sch 67 (3):172-176.

59. Neeter C, Gustavsson A, Thomee P, Augustsson J, Thomee R, Karlsson J (2006) Development of a strength test battery for evaluating leg muscle power after anterior cruciate ligament injury and reconstruction. Knee Surg Sports Traumatol Arthrosc 14 (6):571-580.

60. Neuman P, Englund M, Kostogiannis I, Friden T, Roos H, Dahlberg LE (2008) Prevalence of tibiofemoral osteoarthritis 15 years after nonoperative treatment of anterior cruciate ligament injury: a prospective cohort study. Am J Sports Med 36 (9):1717-1725.

61. Neuman P, Kostogiannis I, Friden T, Roos H, Dahlberg LE, Englund M (2009) Patellofemoral osteoarthritis 15 years after anterior cruciate ligament injury--a prospective cohort study. Osteoarthritis Cartilage 17 (3):284-290.

62. Noyes FR, Barber SD, Mangine RE (1991) Abnormal lower limb symmetry determined by function hop tests after anterior cruciate ligament rupture. Am J Sports Med 19 (5):513-518.

63. Nyland J, Cottrell B, Harreld K, Caborn DN (2006) Self-reported outcomes after anterior cruciate ligament reconstruction: an internal health locus of control score comparison. Arthroscopy 22 (11):1225-1232.

64. Oiestad BE, Engebretsen L, Storheim K, Risberg MA (2009) Knee osteoarthritis after anterior cruciate ligament injury: a systematic review. Am J Sports Med 37 (7):14341443.

65. Oiestad BE, Holm I, Aune AK, Gunderson R, Myklebust G, Engebretsen L, Fosdahl MA, Risberg MA (2010) Knee function and prevalence of knee osteoarthritis after anterior 
cruciate ligament reconstruction: a prospective study with 10 to 15 years of follow-up. Am J Sports Med 38 (11):2201-2210.

66. Oiestad BE, Holm I, Engebretsen L, Risberg MA (2010) The association between radiographic knee osteoarthritis and knee symptoms, function and quality of life 10-15 years after anterior cruciate ligament reconstruction. Br J Sports Med.

67. Oiestad BE, Holm I, Gunderson R, Myklebust G, Risberg MA (2010) Quadriceps muscle weakness after anterior cruciate ligament reconstruction: a risk factor for knee osteoarthritis? Arthritis Care Res (Hoboken) 62 (12):1706-1714.

68. Orchard J, Seward H, McGivern J, Hood S (2001) Intrinsic and extrinsic risk factors for anterior cruciate ligament injury in Australian footballers. Am J Sports Med 29 (2):196-200.

69. Ostenberg A, Roos E, Ekdahl C, Roos H (1998) Isokinetic knee extensor strength and functional performance in healthy female soccer players. Scand J Med Sci Sports 8 (5 Pt 1):257-264.

70. Osteras H, Augestad LB, Tondel S (1998) Isokinetic muscle strength after anterior cruciate ligament reconstruction. Scand J Med Sci Sports 8 (5 Pt 1):279-282.

71. Palmieri-Smith RM, Thomas AC (2009) A neuromuscular mechanism of posttraumatic osteoarthritis associated with ACL injury. Exerc Sport Sci Rev 37 (3):147-153.

72. Palmieri-Smith RM, Thomas AC, Wojtys EM (2008) Maximizing quadriceps strength after ACL reconstruction. Clin Sports Med 27 (3):405-424, vii-ix.

73. Petschnig R, Baron R, Albrecht M (1998) The relationship between isokinetic quadriceps strength test and hop tests for distance and one-legged vertical jump test following anterior cruciate ligament reconstruction. J Orthop Sports Phys Ther 28 (1):23-31.

74. Pfeifer K, Banzer W (1999) Motor performance in different dynamic tests in knee rehabilitation. Scand J Med Sci Sports 9 (1):19-27.

75. Pinczewski LA, Lyman J, Salmon LJ, Russell VJ, Roe J, Linklater J (2007) A 10-year comparison of anterior cruciate ligament reconstructions with hamstring tendon and patellar tendon autograft: a controlled, prospective trial. Am J Sports Med 35 (4):564574.

76. Podlog L, Dionigi RA (2009) Psychological need fulfillment among workers in an exercise intervention: a qualitative investigation. Res Q Exerc Sport 80 (4):774-787.

77. Pujol N, Blanchi MP, Chambat P (2007) The incidence of anterior cruciate ligament injuries among competitive Alpine skiers: a 25-year investigation. Am J Sports Med 35 (7):1070-1074.

78. Risberg MA, Ekeland A (1994) Assessment of functional tests after anterior cruciate ligament surgery. J Orthop Sports Phys Ther 19 (4):212-217.

79. Risberg MA, Holm I, Myklebust G, Engebretsen L (2007) Neuromuscular training versus strength training during first 6 months after anterior cruciate ligament reconstruction: a randomized clinical trial. Phys Ther 87 (6):737-750.

80. Risberg MA, Holm I, Tjomsland O, Ljunggren E, Ekeland A (1999) Prospective study of changes in impairments and disabilities after anterior cruciate ligament reconstruction. J Orthop Sports Phys Ther 29 (7):400-412.

81. Roos EM (2005) Joint injury causes knee osteoarthritis in young adults. Curr Opin Rheumatol 17 (2):195-200.

82. Ross MD, Irrgang JJ, Denegar CR, McCloy CM, Unangst ET (2002) The relationship between participation restrictions and selected clinical measures following anterior cruciate ligament reconstruction. Knee Surg Sports Traumatol Arthrosc 10 (1):10-19.

83. Salmon L, Russell V, Musgrove T, Pinczewski L, Refshauge K (2005) Incidence and risk factors for graft rupture and contralateral rupture after anterior cruciate ligament reconstruction. Arthroscopy 21 (8):948-957. 
84. Salmon LJ, Pinczewski LA, Russell VJ, Refshauge K (2006) Revision anterior cruciate ligament reconstruction with hamstring tendon autograft: 5- to 9-year follow-up. Am J Sports Med 34 (10):1604-1614.

85. Seon JK, Song EK, Park SJ (2006) Osteoarthritis after anterior cruciate ligament reconstruction using a patellar tendon autograft. Int Orthop 30 (2):94-98.

86. Shah VM, Andrews JR, Fleisig GS, McMichael CS, Lemak LJ (2010) Return to play after anterior cruciate ligament reconstruction in National Football League athletes. Am J Sports Med 38 (11):2233-2239.

87. Smith FW, Rosenlund EA, Aune AK, MacLean JA, Hillis SW (2004) Subjective functional assessments and the return to competitive sport after anterior cruciate ligament reconstruction. Br J Sports Med 38 (3):279-284.

88. Soligard T, Nilstad A, Steffen K, Myklebust G, Holme I, Dvorak J, Bahr R, Andersen TE (2010) Compliance with a comprehensive warm-up programme to prevent injuries in youth football. Br J Sports Med 44 (11):787-793.

89. Sward P, Kostogiannis I, Roos H (2010) Risk factors for a contralateral anterior cruciate ligament injury. Knee Surg Sports Traumatol Arthrosc 18 (3):277-291.

90. Thomee P, Wahrborg P, Borjesson M, Thomee R, Eriksson BI, Karlsson J (2008) Selfefficacy of knee function as a pre-operative predictor of outcome 1 year after anterior cruciate ligament reconstruction. Knee Surg Sports Traumatol Arthrosc 16 (2):118127.

91. Thomee R, Neeter C, Gustavsson A, Thomee P, Augustsson J, Eriksson B, Karlsson J (2011) Variability in leg muscle power and hop performance after anterior cruciate ligament reconstruction: A two-year prospective study. Submitted.

92. Thorstensson CA, Henriksson M, von Porat A, Sjodahl C, Roos EM (2007) The effect of eight weeks of exercise on knee adduction moment in early knee osteoarthritis--a pilot study. Osteoarthritis Cartilage 15 (10):1163-1170.

93. Thorstensson CA, Petersson IF, Jacobsson LT, Boegard TL, Roos EM (2004) Reduced functional performance in the lower extremity predicted radiographic knee osteoarthritis five years later. Ann Rheum Dis 63 (4):402-407.

94. Tripp DA, Stanish W, Ebel-Lam A, Brewer BW, Birchard J (2007) Fear of reinjury, negative affect, and catastrophising predicting return to sport in recreational athletes with anterior cruciate ligament injuries at 1 year postsurgery. Rehabilitation Psychology 52:74-81.

95. Walden M, Hagglund M, Ekstrand J (2006) High risk of new knee injury in elite footballers with previous anterior cruciate ligament injury. Br J Sports Med 40 (2):158-162; discussion 158-162.

96. Webster KE, Feller JA, Lambros C (2008) Development and preliminary validation of a scale to measure the psychological impact of returning to sport following anterior cruciate ligament reconstruction surgery. Phys Ther Sport 9 (1):9-15.

97. Wells L, Dyke JA, Albaugh J, Ganley T (2009) Adolescent anterior cruciate ligament reconstruction: a retrospective analysis of quadriceps strength recovery and return to full activity after surgery. J Pediatr Orthop 29 (5):486-489.

98. Wernbom M, Augustsson J, Thomee R (2007) The influence of frequency, intensity, volume and mode of strength training on whole muscle cross-sectional area in humans. Sports Med 37 (3):225-264.

99. Wojtys EM, Huston LJ (2000) Longitudinal effects of anterior cruciate ligament injury and patellar tendon autograft reconstruction on neuromuscular performance. Am $\mathbf{J}$ Sports Med 28 (3):336-344. 
100. von Porat A, Henriksson M, Holmstrom E, Roos EM (2007) Knee kinematics and kinetics in former soccer players with a 16-year-old ACL injury--the effects of twelve weeks of knee-specific training. BMC Musculoskelet Disord 8:35.

101. von Porat A, Roos EM, Roos H (2004) High prevalence of osteoarthritis 14 years after an anterior cruciate ligament tear in male soccer players: a study of radiographic and patient relevant outcomes. Ann Rheum Dis 63 (3):269-273.

102. Wright RW, Dunn WR, Amendola A, Andrish JT, Bergfeld J, Kaeding CC, Marx RG, McCarty EC, Parker RD, Wolcott M, Wolf BR, Spindler KP (2007) Risk of tearing the intact anterior cruciate ligament in the contralateral knee and rupturing the anterior cruciate ligament graft during the first 2 years after anterior cruciate ligament reconstruction: a prospective MOON cohort study. Am J Sports Med 35 (7):11311134.

103. Xergia SA, McClelland JA, Kvist J, Vasiliadis HS, Georgoulis AD (2011) The influence of graft choice on isokinetic muscle strength 4-24 months after anterior cruciate ligament reconstruction. Knee Surg Sports Traumatol Arthrosc 19 (5):768-780.

104. Yoon T, Hwang J (2000) Comparison of eccentric and concentric isokinetic exercise testing after anterior cruciate ligament reconstruction. Yonsei Med J 41 (5):584-592. 